\title{
Double-blind prospective randomized study comparing topical mupirocin and placebo for the prevention of infection associated with central venous catheters
}

John M Conly MD, Robert Rennie PhD, Leonard Tan MD PhD, Colin Bagg BSC, Karen Stein RT, Barb Peters RN

\begin{abstract}
JM CONLY, R RENNIE, L TAN, C BAGG, K STEIN, B PETERS. Double-blind prospective randomized study comparing topical mupirocin and placebo for the prevention of infection associated with central venous catheters. Can J Infect Dis 1997;8(4):214-221.

OBJECTIVE: To compare the incidence of exit site colonization, local catheter-related infection and catheter-related bacteremia in patients randomized to receive either topical $2 \%$ mupirocin or placebo at the catheter exit site. PATIENTS AND METHODS: Patients requiring central venous catheters for more than three days were randomized to receive in a double-blind fashion either topical mupirocin or an identical placebo at the exit site three times weekly at the time of dressing change. Insertion, site care and removal of catheters were standardized. Serial semiquantitataive cultures of the skin at the catheter insertion site were performed using a sterile $25 \mathrm{~cm}^{2}$ template. The distal and proximal catheter segments were cultured using a standardized semiquantitative technique, and any suspect catheter-related bacteremia was investigated with two sets of peripheral blood cultures, a $10 \mathrm{~mL}$ sample of infusate and clinical assessment. Both univariate and multivariate analyses were conducted on individual risk factors to determine factors that might influence the outcomes of local or systemic catheter-related infection.

RESULTS: Local catheter-related infection (defined as more than 15 colony forming units [cfu] on culture of the proximal or distal catheter segment) occurred in six of $57(10.5 \%)$ in the mupirocin group versus 18 of $69(26 \%)$ in the placebo group $(\mathrm{P}<0.05)$ for the distal catheter segments and in one of $40(2.5 \%)$ versus 13 of $47(27.6 \%)$ for the proximal segments in the mupirocin and placebo groups $(\mathrm{P}<0.006)$, respectively. Catheter-related bacteremia occurred in one of $57(1.8 \%)$ of the mupirocin group but in five of $69(7.2 \%)$ of the placebo group $(\mathrm{P}=0.15)$. Stepwise logistic regression revealed that cutaneous colonization at the insertion site of at least $10^{3} \mathrm{cfu} / \mathrm{mL} / 25 \mathrm{~cm}^{2}$ (OR 2.6 ; CI 1.0 to 6.9) and the use of placebo (OR 3.3; CI 1.2 to 9.0) were significant factors predicting local catheter-related infection; whereas mupirocin was associated with reciprocal protective effect (OR 0.3 ; $95 \%$ CI 0.1 to 0.8 ).

CONCLUSIONS: These findings suggest that patients receiving topical mupirocin at the exit site for long term central venous catheters have significantly less local catheter-related infection, and there is a trend towards less catheterrelated bacteremia.
\end{abstract}

Key Words: Catheters, Mupirocin, Prevention

This study was presented in abstract form at the 18th International Congress of Chemotherapy, Stockholm, Sweden, June 27 to July 2, 1993 Departments of Medicine, Microbiology and Community Health and Epidemiology, University of Saskatchewan, Saskatoon, Saskatchewan Correspondence and reprints: Dr JM Conly, The Toronto Hospital, Toronto General Division, NUW 13-117, 200 Elizabeth Street, Toronto,

Ontario M5G 2C4. Telephone 416-340-4858, fax 416-340-5047, e-mail jconly@torhosp.toronto.on.ca

Received for publication July 16, 1996. Accepted December 18, 1996 


\title{
Étude à double insu prospective randomisée comparant la mupirocine topique et le placebo en prévention de l'infection associée aux cathéters veineux centraux
}

\begin{abstract}
OBJECTIF : Comparer la fréquence de colonisation des sites d'insertion des cathéters, de l'infection locale associée aux cathéters et de la bactériémie associée aux cathéters chez des patients randomisés devant recevoir soit de la mupirocine à $2 \%$ topique ou un placebo appliqué localement.

PATIENTS ET MÉTHODES : Des patients nécessitant des cathéters veineux centraux pour une durée de plus de trois jours ont été randomisés afin de recevoir soit de la mupirocine topique ou un placebo identique appliqué au point d'insertion trois fois par semaine au moment des changements de pansement. L'insertion, l'hygiène des sites et le retrait du cathéter ont été standardisés. Des cultures semi-quantitatives en séries de la peau au site d'insertion du cathéter ont été effectuées à l'aide d'un modèle stérile de $25 \mathrm{~cm}^{2}$. Les segments distal et proximal du cathéter ont été placés en culture à l'aide d'une technique semi-quantitative standardisée et toute bactériémie possiblement associée aux cathéters a fait l'objet de deux séries d'hémocultures périphériques, d'un échantillon de $10 \mathrm{~mL}$ de l'infusat et d'un examen clinique. Des analyses univariées et multivariées ont été effectuées sur les facteurs de risque individuels pour déterminer lesquels pouvaient influer sur le développement de l'infection locale ou systémique associée aux cathéters.

RÉSULTATS : L'infection locale associée aux cathéters (définie comme plus de 15 unités formant colonie (ufc) à la culture des segments de cathéter proximal ou distal) a été observée chez six patients sur 57 du groupe mupirocine $(10,5 \%)$, contre 18 patients sur les 69 du groupe placebo $(26 \%)(P<0,05)$ pour les segments de cathéters distaux et chez un patient sur $40(2,5 \%)$, contre 13 sur $47(27,6 \%)$ respectivement dans les groupes sous mupirocine et sous placebo $(\mathrm{P}<0,006)$ pour les segments proximaux. La bactériémie associée aux cathéters a été observée chez un patient sur les 57 du groupe mupirocine $(1,8 \%)$ et chez cinq patients sur les $69 \mathrm{du}$ groupe placebo $(7,2 \%)(P=0,15)$. Une régression logistique en étapes a révélé que la colonisation cutanée au point d'insertion par plus de $10^{3} \mathrm{ufc} / \mathrm{mL} / 25 \mathrm{~cm}$ (RR 2,6; IC 1,0 à 6,9) et l'emploi de placebo (RR 3,3; IC 1,2 à 9,0) étaient des facteurs significatifs de prévisibilité de l'infection locale associée aux cathéters. La mupirocine a été associée à un effet réciproque (RR 0,3; IC 0,1 à 0,8$)$. CONCLUSIONS : Ces observations donnent à penser que les patients qui reçoivent de la mupirocine topique au site d'insertion des cathéters veineux centraux installés à long terme risquent significativement moins de souffrir d'infection locale associée aux cathéters et la tendance est la même dans le cas de la bactériémie associée aux cathéters.
\end{abstract}

C atheter-related septicemia is generally cited as the most frequent serious complication related to the use of central venous catheters (1-5). The incidence of catheter-related septicemia and local catheter-related infection varies depending upon the patient population and the purpose for which the catheter has been inserted, but rates of catheter-related bacteremia have ranged from $3.8 \%$ to $27 \%$ and of local catheterrelated infection from $4 \%$ to $42 \%(6-18)$ in several prospective studies. Although catheter-related infections may be related to contaminated infusate (3), hematogenous seeding (8) or hub colonization with contiguous intralumenal colonization $(1,19,20)$, the majority have been associated with endogenous micro-organisms which are prevalent on the skin surrounding the catheter exit site (21-23). Two recent studies examining the pathogenesis of pulmonary arterial (24) and central venous catheter-related infection (25) using molecular subtyping techniques have confirmed this correlation, finding that over $80 \%$ of the cases of local infection of the cannula and of bacteremia are secondary to pericatheter skin flora. Theoretically, application of topical antimicrobial agents to the catheter insertion site should be an effective preventive strategy, but clinical trials of topical polyantibiotic ointments on peripheral venous catheters have shown little benefit (26-28). Although topical povidone-iodine ointment $(29,30)$ has been recommended for application at the central venous catheter exit site, few studies have evaluated the efficacy of the application of topical antimicrobial agents at the catheter exit site for the prevention of central catheter-related infections. Mupirocin, a new nonsystemic antibiotic with significant antistaphylococcal activity $(31,32)$, may be efficacious in this regard. A recent prospective trial of 218 cardiothoracic pa- tients randomized to receive tincture of iodine skin preparation, followed by application of sterile $2 \%$ calcium mupirocin versus no application for intravascular cannulae inserted for short term (48 h) hemodynamic monitoring, found a fivefold reduction in the proportion of local catheter-related infection in the mupirocin group (33). Because no published trials demonstrate a significantly reduced rate of both local catheterrelated infection and catheter-related bacteremia with the use of a topical antimicrobial agent at the exit site of central catheters, we designed a study to evaluate the efficacy of mupirocin in this regard. The study compared the incidence of exit site colonization, local catheter-related infection and catheter-related bacteremia in patients with central catheters inserted for three or more days, prospectively randomized to receive either topical $2 \%$ mupirocin ointment or placebo.

\section{PATIENTS AND METHODS}

Study design: The study was performed at the Royal University Hospital, Saskatoon, Saskatchewan, a 607-bed tertiary care, medical school-affiliated institution over a three-year period between 1989 and 1992. Eligible patients included any patients admitted to any medical, surgical or pediatric ward or the intensive care unit (mixed medical and surgical) with the criterion that they had a central venous catheter inserted for purposes of fluid or drug therapy, parenteral nutrition or hemodynamic monitoring for a duration likely to equal or exceed three days, as determined by the attending service at the time of initial line insertion. This eligibility criterion increases the opportunity of finding catheter-related sepsis $(30,34,35)$. All percutaneously inserted single and multilumen catheters were composed of polyurethane and all 'tunnelled' indwelling 
catheters were composed of silicone. Polyurethane central venous lines were inserted at the bedside using a prescribed aseptic technique. Attachable silver impregnated cuffs were not used in this study. Physicians used a 2 min surgical hand scrub with either $10 \%$ povidone-iodine or $2 \%$ chlorhexidine, sterile gloves, masks, a povidone-iodine scrub of the insertion site, small sterile drapes around the insertion site and a sterile long-sleeved gown. Subclavian or internal jugular routes were used at the discretion of the attending physician. Following insertion and after obtaining informed consent, patients were randomly allocated by hospital number (last digit, with odds receiving one treatment and evens the other) to one of two groups, sterile gauze dressings replaced every $48 \mathrm{~h}$ with or without a topical $2 \%$ mupirocin ointment (Bactroban, SmithKline Beecham) in a soft paraffin base. The application of the $2 \%$ mupirocin or placebo ointment occurred following removal of the initial pressure dressing. Silicone tunnelled lines were inserted in operating rooms under aseptic conditions. Both investigators and patients were blinded as to the application of the topical antimicrobial or the use of a placebo ointment (soft paraffin base only) that was identical to the mupirocin ointment except for the presence of the mupirocin.

All catheters were cared for in a similar manner. All connecting tubings were changed every $72 \mathrm{~h}$. Sterile gauze and tape dressings were changed three times weekly on Monday, Wednesday and Friday. At each dressing change and at the time of removal, the site was visually inspected by the research nurse, and the condition of the dressing observed. The condition of the dressing was assessed as good if the dressing was intact, not soiled and had no evidence of lifting, and poor if any of these parameters was not met. A review of the medical record procedure notes from the time of insertion was conducted, and the insertion recorded as difficult if indicated as such by the inserting physician. A standard cleansing procedure was followed before the placement of a new dressing. A $15 \mathrm{~s}$ handscrub with either $10 \%$ povidone-iodine or $2 \%$ chlorhexidine was used along with a mask, sterile drapes and a 'no-touch technique'. After the old dressing was carefully removed, a $5 \mathrm{~cm}$ radius of skin surrounding the insertion site was subjected to an application of $70 \%$ isopropyl alcohol followed by application of a $10 \%$ povidone-iodine solution. This procedure included the proximal $3 \mathrm{~cm}$ of the catheter. Either mupirocin or placebo was applied to the skin and catheter site, and a new sterile gauze dressing was applied. All other manipulations of the catheter were performed by a specific protocol, using gloves, mask and gown.

Microbiological methods: Semiquantitative cultures of the skin at the site of a catheter insertion were performed at each dressing change before cleaning and ointment application. A $5 \mathrm{~cm} \times 5 \mathrm{~cm}$ sterile template was placed over the catheter insertion site, and a sterile cotton-tipped applicator moistened with $0.01 \mathrm{M}$ phosphate-buffered saline was used to culture the surface of the skin within the template. The applicators were then transferred into tubes containing $1 \mathrm{~mL}$ of trypticase soy broth, vortexed vigorously for $90 \mathrm{~s}$ and then cultured quantitatively. Microbial species were identified using standard methods (36).

All catheters were removed by a specific protocol, either electively or in the event of catheter-related sepsis or other complication. A template skin culture was obtained at the time of catheter removal, and following this the puncture site was cleaned with $70 \%$ isopropyl alcohol. The catheter was withdrawn with sterile forceps, and the external portion was directed upward and away from the skin surface to prevent any possible contamination from withdrawal of the catheter. Two segments of the catheter were cultured, the distal $3 \mathrm{~cm}$ long segment catheter tip and the proximal subcutaneous $3 \mathrm{~cm}$ long portion. These samples were placed in sterile tubes and sent immediately to the laboratory. Distal and proximal segments of the catheter were cultured using the semiquantitative technique described by Maki et al (37) involving rolling the segments firmly across the surface of agar. All isolates were identified by standard methods. Species of coagulasenegative staphylococci were speciated using the API-Staph Ident (API Laboratory Products), and production of extracellular slime substance was determined according to the methods of Christensen et al (38). Organisms isolated from either the proximal or distal catheter tip and blood cultures were characterized by antibiogram and plasmid analysis (39).

Suspected catheter-related sepsis: If any patient developed fever, chills and clinical features of sepsis, two sets of peripheral blood cultures and a $10 \mathrm{~mL}$ sample of infusate were sent for culture. In addition, a blood culture was drawn from the line. After $24 \mathrm{~h}$, if no other source of infection was identified, the origin of clinical sepsis was assumed to be the catheter, and it was removed. A search for other sources of infection included physical examination, urine and blood cultures and, if indicated, a chest radiograph.

The following definitions were applied throughout the course of the study, modified from those of Stiges-Serra et al (40). Systemic catheter-related bacteremia occurred when the same organism (identical species and antibiogram) was isolated from catheter tip and blood in a patient who was clinically septic with no identifiable source of the sepsis; local catheter-related infection was the presence of at least 15 colony forming units ( $\mathrm{cfu}$ ) on semiquantitative culture on either or both of the proximal or distal catheter segments; and catheter colonization was considered the presence of less than 15 cfu on semiquantitative culture of either proximal or distal segments.

The study protocol was similar for both subclavian and tunnelled silicone lines. If a double lumen line was encountered, both channels were studied but results were recorded as if one line were present.

Statistical analysis: In the univariate analysis, discrete variables were compared using ${ }^{2}$ or Fisher's exact test, as appropriate, and continuous variables were compared using the Student's $t$ test for normally distributed data and the Kruskal Wallis $\mathrm{H}$ test for data not normally distributed. The significance of differences in the numbers of quantitative exit site cultures, which were $10^{3} \mathrm{cfu} / \mathrm{mL} / 25 \mathrm{~cm}^{2}$ or greater, and local and systemic catheter-related infections between the two groups were analyzed using ${ }^{2}$ and Fisher's exact tests, as appropriate. To identify individual risk factors that might influence the occurrence of local catheter-related infection or 
Conly et al

TABLE 1

Demographic features and comparability of patients with central venous catheters

\begin{tabular}{|c|c|c|c|c|}
\hline \multirow[b]{2}{*}{ Characteristic } & \multicolumn{2}{|c|}{ Group } & \multirow[b]{2}{*}{$\mathbf{P}$} & \multirow[b]{2}{*}{ Odds ratio } \\
\hline & $2 \%$ Mupirocin $(n=57)$ & Placebo $(n=69)$ & & \\
\hline Age (year) & $60.3 \pm 2.0$ & $56.4 \pm 2.1$ & 0.24 & - \\
\hline Male:Female & $30: 27$ & $41: 28$ & 0.88 & 0.76 \\
\hline \multicolumn{5}{|l|}{ Season } \\
\hline (spring/summer/fall/winter) & 10:10:10:27 & $19: 14: 11: 25$ & 0.99 & 1.0 \\
\hline Number of applications & 4.2 & 3.8 & 0.052 & - \\
\hline \multicolumn{5}{|l|}{ Catheter type: } \\
\hline Polyurethane & 52 & 66 & 0.25 & 0.47 \\
\hline Silicone & 4 & 3 & 0.37 & 1.66 \\
\hline Other & 1 & 0 & 0.45 & - \\
\hline Reinsertions & 6 & 6 & 0.84 & 1.24 \\
\hline \multicolumn{5}{|l|}{ Site of insertion } \\
\hline Jugular & 21 & 26 & 0.92 & 0.96 \\
\hline Subclavian & 36 & 43 & & \\
\hline ‘Difficult' insertion & 5 & 6 & 0.98 & 1.01 \\
\hline \multicolumn{5}{|l|}{ Reason for insertion } \\
\hline Total parenteral nutrition & 51 & 63 & 0.96 & 0.81 \\
\hline Other & 6 & 6 & & \\
\hline \multicolumn{5}{|l|}{ Dressing condition } \\
\hline Good & 47 & 56 & 0.84 & 1.09 \\
\hline Poor & 10 & 13 & & \\
\hline Length stay (days) & $52.5 \pm 5.4$ & $47.1 \pm 6.6$ & 0.54 & - \\
\hline Duration of catheterization (days) & $14.3 \pm 1.6$ & $14.1 \pm 1.9$ & 0.34 & - \\
\hline \multicolumn{5}{|l|}{ Primary diagnosis } \\
\hline Gastrointestinal disease & 37 & 43 & 0.70 & 1.12 \\
\hline Neoplasm & 9 & 16 & 0.41 & 0.62 \\
\hline Other & 11 & 10 & 0.63 & 1.41 \\
\hline Devices & 28 & 29 & 0.88 & 1.25 \\
\hline Antibiotics & 23 & 27 & 0.96 & 1.05 \\
\hline Steroids & 7 & 10 & 0.92 & 0.83 \\
\hline \multicolumn{5}{|l|}{ Procedures } \\
\hline Laparotomy & 4 & 9 & 0.42 & 0.50 \\
\hline Thoracotomy & 2 & 1 & 0.59 & 2.47 \\
\hline None & 9 & 6 & 0.31 & 1.97 \\
\hline
\end{tabular}

Data are for number of catheter insertions or mean $\pm S E$

catheter-related bacteremia, significant variables from the univariate analysis $(\mathrm{P}<0.1)$ obtained at the time of catheter removal were subjected to stepwise logistic regression analysis (Egret, Statistics and Epidemiology Research Corporation, Washington). Local catheter-related infection and catheterrelated bacteremia were considered dependent variables.

\section{RESULTS}

There were 187 randomizations for catheter insertion for the study. Twenty-two were excluded for the following reasons: 14 had central catheters for less than three days, three had a transparent dressing rather than a gauze dressing, two had randomization errors, one patient withdrew from the study, one patient did not sign the consent form and one patient was bacteremic at the time of catheter insertion. A total of 165 catheter insertions were available for analysis representing 143 patients, including 79 insertions in 69 patients in the mupirocin group and 86 insertions in 74 patients in the placebo group. Of the 165 insertions, 149 (90.3\%) were new insertions and $16(9.7 \%)$ were reinsertions over a guidewire at the same site as the initial insertion. Sixty-nine (80.2\%) catheters were recovered from the 86 insertions in the placebo group, and 57 (72.1\%) catheters were recovered from the 79 insertions in the mupirocin group. Results were analyzed for first insertions and for first insertions combined with reinsertions. Results presented in the tables are for the combined group of first insertions and reinsertions because this represents a more conservative analytic approach and is most relevant to actual clinical practice. Results on the outcomes of interest for first insertions are the only ones presented in the text. 


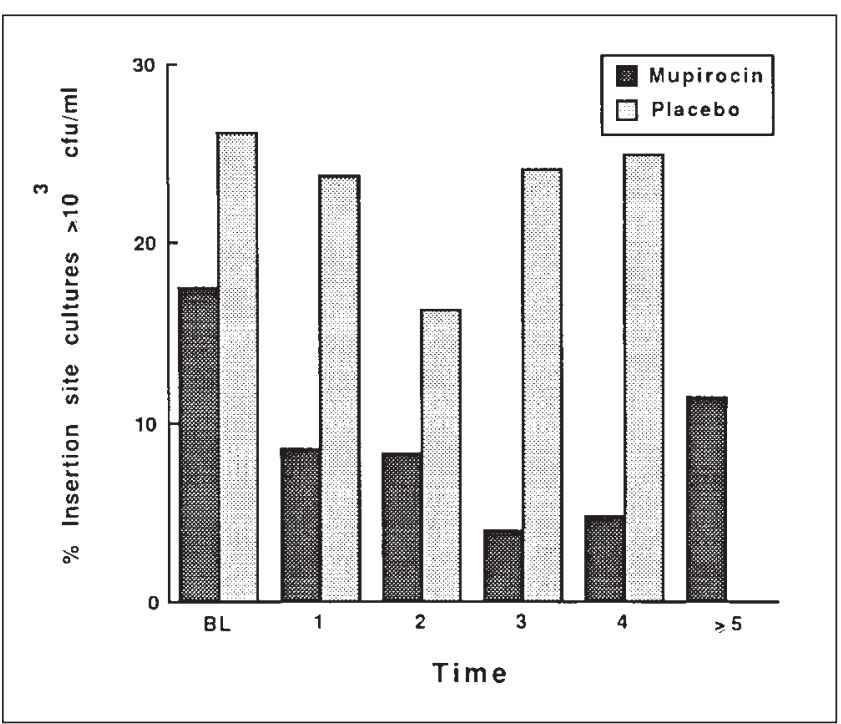

Figure 1) Percentage of insertion site cultures $10^{3}$ colony forming units (cfu) $/ \mathrm{mL} / 25 \mathrm{~cm}^{2}$ or greater (intervals of $48 \mathrm{~h}$ ) for all isolates. There were significantly fewer $(P \leq 0.01)$ exit site cultures $10^{3}$ cfu or greater in the mupirocin than in placebo group following the third application of the ointment. BL Baseline cultures of exit site at time of initial randomization

Demographic features and comparability of the 57 patients in the mupirocin group and the 69 patients in the placebo group from whom distal catheter tips were recovered are shown in Table 1. The two treatment groups were comparable with respect to all the variables that were analyzed including primary and secondary diagnoses. The primary reason for insertion was the administration of total parenteral nutrition, with $89.5 \%$ and $91.3 \%$ of the catheters in the mupirocin and placebo groups, respectively, inserted for this reason. Prolonged length of stay, duration of catheterization, frequency of device use and number of patients receiving antimicrobial agents reflected this population's high risk for nosocomial infection.

There were a total of 228 quantitative exit site cultures in the mupirocin group versus 248 in the placebo groups. The baseline cultures for each of the two groups was not significantly different with a mean \pm SE of $4.56 \pm 4.1 \times 10^{4}$ for the mupirocin group and $4.48 \pm 4.1 \times 10^{4} \mathrm{cfu} / \mathrm{mL} / 25 \mathrm{~cm}^{2}$ for the placebo group. However, the proportion of exit site cultures with $10^{3} \mathrm{cfu} / \mathrm{mL} / 25 \mathrm{~cm}^{2}$ or greater was higher in the placebo group following the first application of cream and was significantly higher following the third application in the placebo group compared with the mupirocin group. This finding remained significant beyond the fifth dressing change. This difference was noted when all isolates were considered and when only staphylococcal isolates were considered (Figures 1,2 ). No significant difference was noted when isolates other than staphylococci were considered, not an unexpected finding given the limited spectrum of activity of mupirocin $(31,32)$. Further individual analysis beyond five applications was not considered reliable because of the relatively small number of applications that were available for comparison between the two groups $(n<20)$. Overall, there was a significantly greater number of exit site cultures $10^{3} \mathrm{cfu} / \mathrm{mL}$ or greater in the pla-

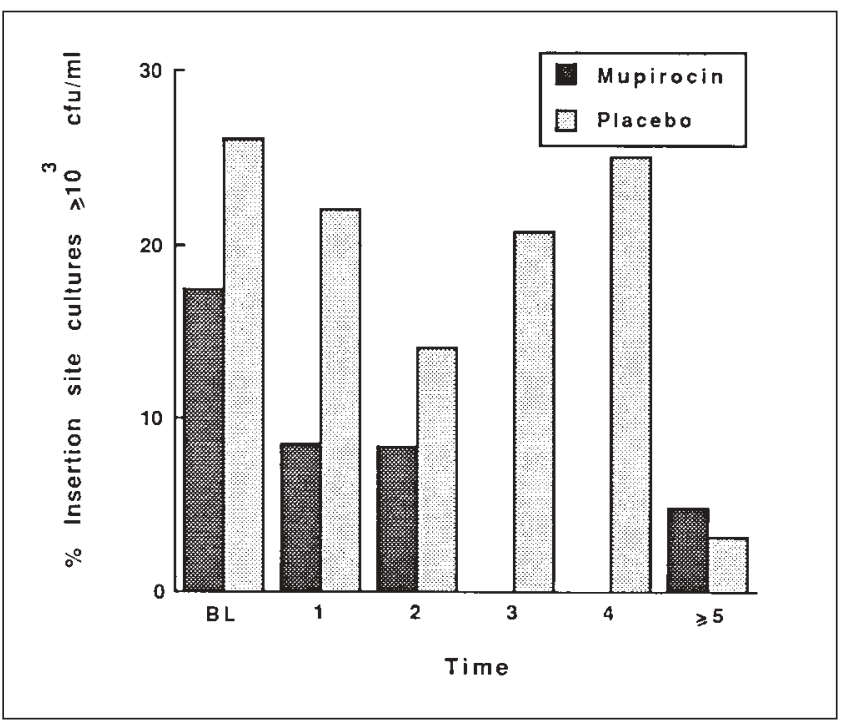

Figure 2) Percentage of insertion site cultures $10^{3}$ colony forming units (cfu) $/ \mathrm{mL} / 25 \mathrm{~cm}^{2}$ or greater (intervals of $48 \mathrm{~h}$ ) for all staphylococcal isolates. There were significantly fewer $(P \leq 0.01)$ exit site cultures $10^{3}$ cfu or greater in the mupirocin than in placebo group following the third application of the ointment. BL Baseline cultures of exit site at time of initial randomization

\section{TABLE 2}

Episodes of local catheter-related infection (15 colony forming units or more on semiquantitative culture) in patients receiving either mupirocin or placebo at the catheter exit site

\begin{tabular}{lccc}
\hline Infection & $\begin{array}{c}\text { Mupirocin } \\
(\mathbf{\%}) \mathbf{n}=\mathbf{5 7}\end{array}$ & $\begin{array}{c}\text { Placebo (\%) } \\
\mathbf{n = 6 9}\end{array}$ & $\mathbf{P}$ \\
\hline Local catheter-related & & & \\
$\quad$ Distal & $6(10.5)$ & $18(26.1)$ & 0.05 \\
$\quad$ Proximal* & $1(2.5)$ & $13(27.7)$ & 0.006 \\
Tunnel infection & $2(3.5)$ & 0 & NS \\
Catheter-related & $1(1.75)$ & $5(5.7)$ & 0.15 \\
bacteremia & & & \\
*Mupirocin $n=40 ;$ placebo $n=47$. NS Not significant &
\end{tabular}

cebo group (49 of 248) than in the mupirocin groups ( 25 of 228) $(\mathrm{P}<0.005)$. The organisms identified that accounted for the cutaneous colonization at the exit site were predominantly coagulase-negative staphylococci (more than $80 \%$ ).

One hundred and twenty-six catheters from 165 insertions were available for microbiological analysis, representing $76.4 \%$ of all catheters. Catheters that were not available for culture were either inadvertently discarded after removal, remained with the patient at the time of discharge or were not removed according to the protocol. Of the 69 catheters in the placebo group, analysis of the distal tip revealed local catheter-related infection (Table 2 ) in $18(26.1 \%)$ versus only six of $57(10.5 \%)$ in the mupirocin group $(\mathrm{P}<0.05)$. Comparison of the local catheter-related infection rates for the proximal catheter segment for the two groups revealed 13 of 47 $(27.7 \%)$ in the placebo group versus one of $40(2.5 \%)$ in the mupirocin group $(\mathrm{P}=0.006)$. An analysis of local catheterrelated infection rates for the distal and proximal catheter segments revealed that quantitative site cultures $10^{3} \mathrm{cfu} / \mathrm{mL}$ or 
TABLE 3

Microorganisms causing local catheter-related infections and catheter-related bacteremia in $\mathbf{5 7}$ and $\mathbf{6 9}$ catheter insertions receiving mupirocin or placebo, respectively, at the catheter exit site

\begin{tabular}{lcc}
\hline Organism & 2\% Mupirocin & Placebo \\
\hline Local catheter-related infection & & \\
Coagulase-negative & 4 & 18 \\
$\quad$ Staphylococci & 1 & - \\
Pseudomonas aeruginosa & 1 & 2 \\
Staphylococcus aureus & - & 2 \\
$\quad$ Corynebacterium & & \\
Catheter-related sepsis & - & 3 \\
$\quad$ Coagulase-negative & & \\
staphylococci & 1 & 2 \\
$\quad$ S aureus & & \\
\hline
\end{tabular}

greater were significantly $(\mathrm{P}<0.05)$ associated with local infection. No infusates were found to be culture positive. Only two tunnel infections were documented, and both were in the mupirocin group. There was one case of bacteremia in the mupirocin group but five in the placebo group $(\mathrm{P}=0.15)$.

Reanalysis of all the data, including patient demographic features, exit site quantitative cultures, local catheter-related infections of both proximal and distal segments, and catheter-related sepsis, does not alter the overall findings if all 'reinsertions' are excluded from the analysis. Of 16 instances where catheters were reinserted over a guidewire, catheter tips were recovered in 12 , with local catheter-related infection occurring in two of the reinsertions (one in each of the mupirocin and placebo groups). For the first insertions only, the local catheter infection rate for the proximal catheter segment was 11 of $44(25 \%)$ in the placebo group versus one of $35(2.9 \%)$ in the mupirocin group $(\mathrm{P}=0.02)$ and for the distal catheter segment was 17 of 63 (27\%) versus five of 51 (9.8\%) in the two groups, respectively $(\mathrm{P}=0.04)$. Similarly, there was one bacteremia in the mupirocin group but five in the placebo group $(\mathrm{P}=0.16)$. Although the total number of reinsertions is small, the incidence of local catheter-related infections in this group does not differ significantly from the rate (22 of $114 ; 19.3 \%$ ) of local catheter-related infection for initial insertions.

Patients whose catheter tips were not cultured were followed carefully for the occurrence of bacteremia to assess if it may have been catheter-related. Prospective follow-up of these 39 catheter insertions throughout the course of the study by the research nurse revealed no instances of bacteremia that did not have a readily identifiable secondary focus or source.

Organisms isolated from the distal catheter tips and from episodes of catheter-related sepsis are given in Table 3 . The majority of the isolates (78.6\%) were coagulase-negative staphylococci. Of the 22 strains of coagulase-negative staphylococci, 16 were Staphylococcus epidermidis and there were two strains each of Staphylococcus heamolyticus, Staphylococcus warnerii and Staphylococcus capitis. The majority of the staphylococcal isolates were slime-producing and multiply antibiotic resistant.

The organisms responsible for the five episodes of catheter-related bacteremia were S epidermidis (3) and Staphylococcus aureus (2). Isolated organisms identified from the blood cultures were identical to the organisms isolated from the distal catheter tips on the basis of an extended antibiogram, biotyping and plasmid analysis. All staphylococcal isolates from blood and from distal catheter tips were tested for resistance to mupirocin using a standard agar dilution technique with cation-adjusted Mueller-Hinton agar and inoculation using a Steere's replicator; no resistance to mupirocin was found.

Stepwise logistic regression analysis revealed the presence of $10^{3} \mathrm{cfu} / \mathrm{mL}$ or greater for the cultured area (RR 2.6, 95\% CI 1.0 to 6.9 ) was an independent variable that predicted local catheter-related infection. The use of the placebo was also independently associated with a risk of local catheter infection (RR 3.3, 95\% CI 1.2 to 9.0), suggesting a reciprocal protective effect from the use of mupirocin.

\section{DISCUSSION}

Results of this trial suggest that for individuals with central catheters in place for at least three days, the use of $2 \%$ mupirocin is significantly more effective than placebo in the prevention of local catheter-related infection. There is also a trend towards a reduction in bacteremia. All patients in whom catheter insertions were performed were well-matched, with both patients and investigators blinded to the presence or absence of active mupirocin, the chance of any significant bias was minimized. Results of the study were also analyzed by the investigators in a blinded fashion.

Mupirocin, formerly termed pseudomonic acid A, is a novel topical antibiotic with a structure that is unrelated to other currently known antibiotics $(41,42)$. Its mechanism of action is inhibition of bacterial protein and RNA synthesis, through inhibition of isoleucyl-transfer RNA synthetase. It has excellent in vitro activity against staphylococci and most streptococci, but other aerobic and anaerobic Gram-positive bacteria are only moderately susceptible $(41,42)$. Mupirocin has little activity against Gram-negative bacteria with the exception of Hemophilus influenzae and several Neisseria species. The drug is currently available in two formulations, a polyethylene glycol vehicle base and a soft paraffin base, the latter of which is not yet marketed in Canada. It has proven to be effective in the management of certain staphylococcal and streptococcal cutaneous infections (41) and in the administration of nasal carrier states for individuals colonized with $S$ aureus $(43,44)$. Little resistance to this compound has been reported.

Given the acknowledged importance of the endogenous cutaneous microflora in the pathogenesis of most intravascular device-related infections $(22,26,27)$, measures to reduce colonization at the cannula exit site have always been of high priority. Two prospective studies of topical povidone-iodine ointment applied to central venous catheter sites have been conducted $(29,30)$, one of which showed no benefit in intensive care unit patients and one of which demonstrated a four- 
fold reduction in the incidence of catheter-related sepsis in hemodialysis patients. Trials of topical polyantibiotic ointments (polymixin, neomycin and bacitracin) on peripheral venous catheters have shown modest benefit (26-28), although there is a suggestion that this occurs at the expense of a higher risk of acquiring fungal colonization and infection (28).

Only one other large prospective study on central catheters has addressed the issue of the prevention of infection of the cannula using application of an antibiotic ointment. Hill and colleagues $(33,45)$ studied 358 central venous catheters inserted for hemodynamic monitoring in 218 patients undergoing cardiothoracic surgery; 172 received application of $2 \%$ mupirocin (paraffin base) just before cannulation and following cannulation at each dressing change, whereas the control group ( $\mathrm{n}=186)$ did not. Although over $90 \%$ of cannulae were removed within $48 \mathrm{~h}$, local catheter-related infection (15 cfu or greater on semiquantitative culture) occurred significantly $(\mathrm{P}<0.001)$ more often in the control group $(25 \%)$ than the mupirocin group $(5 \%)$. No bacteremias were detected in either group. Our study differs from those of Hill et al in several respects, including the patient population, the reason for insertion (primarily total parenteral nutrition) and, most importantly, the length of time that the catheter was in place. Nonetheless, their findings are remarkably similar to those of the current study, with regards to the proportions of local catheter-related infections. With a longer catheter duration, our study design was more likely to detect differences in bacteremia rates.

Rates of catheter-related bacteremia have ranged between $3.8 \%$ and $27 \%$ for central venous cannula, and in our study the overall rate was $4.0 \%$. The overall rate of local catheter-related infection was $19 \%$ in our study, which is consistent with a rate of $24 \%$ reported from a study comparing gauze with transparent dressings, in which similar patients had central catheters inserted for three days or more with a gauze dressing (46). We chose to study central catheters with a gauze dressing because of the acknowledged deleterious effect of transparent dressings on local catheter-related infections and bacteremia (47). Because duration of catheterization is a major determinant of local catheter-related infection $(24,34,35,48,49)$, by choosing patients for our study with a catheter duration of three days or more we were able to optimize the opportunity of finding any catheter-related infection. Logistic regression analysis revealed that the use of placebo and the presence of $10^{3} \mathrm{cfu} / \mathrm{mL} / 25 \mathrm{~cm}^{2}$ or greater at the catheter exit site was significantly associated as an independent risk factor for local catheter-related infections. This latter observation has been previously documented as a risk factor in the pathogenesis of catheter-related infections $(21,22,24,25,47)$. There was a significant difference in the colonization of the skin at the catheter exit site but it was not evident until after the third application of the mupirocin. The reasons for this are not readily apparent, but it is possible that with the reduction of Grampositive flora more Gram-negative flora was present, or that the use of a paraffin-based vehicle promoted growth of certain micro-organisms in both mupirocin-treated and placebo- treated groups. It is recognized that the presence of oils and sebum enhances the proliferation of endogenous microflora on the skin. Nonetheless, the use of mupirocin is associated with significantly less local catheter-related infection.

Two tunnel infections were documented in our study, both in the mupirocin group. One occurred secondary to Pseudomonas aeruginosa which is known to be resistant to mupirocin and the other occurred secondary to $S$ aureus, which was sensitive to the mupirocin. However, the insertion in which this tunnel infection occurred was noted to be very difficult with multiple attempts required for insertion. Excluding patients with tunnel infection, which may cause bacteremia secondary to cellulitis rather than line infection itself, reanalysis of the data for bacteremia yields a significant difference $(P=0.05)$ between the two groups for this outcome. However, given the difficulties differentiating bacteremia secondary to tunnel infection and cellulitis versus bacteremia due to line infection in this setting, it is prudent to apply the most conservative analysis in this setting. Nonetheless, there is still a trend towards less catheter-related bacteremia, which we believe is clinically relevant, and a significant difference in local catheter-related infection in the mupirocin group. It is likely that a larger sample size would be required to show a significant difference in the rates of catheter-related bacteremia between the two groups. Our findings suggest that $2 \%$ mupirocin (paraffin base) applied to the insertion site of long term (three days or more) central venous catheters reduces the infectious complications related to the use of these catheters.

ACKNOWLEDGEMENTS: The authors thank the patients of Royal University Hospital who participated in this study and the nursing staff and house officers who freely committed their time to cooperate with the study requirements. We also thank Ms J Sklarchuk and Ms E Paulino for typing this manuscript. This study was supported by a grant from SmithKline Beecham of Canada. The guidelines for human experimentation as outlined and approved by the Ethics Committee of the University of Saskatchewan were used for this study. Informed written consent was obtained from all participants before study.

\section{REFERENCES}

1. Raad II, Bodey GP. Infectious complications of indwelling vascular catheters. Clin Infect Dis 1992;15:197-210.

2. Collins RN, Braun PA, Zinner SH, Kass EH. Risk of local and systemic infection with polyethylene intravenous catheters. N Engl J Med 1968;279:340-3.

3. Maki DG. Infections associated with intravascular lines. In: Swartz M, Remington JS, eds. Current Topics in Clinical Infectious Disease. New York: McGraw Hill, 1982:309-63.

4. Plumer AL. Principles and Practice of Intravenous Therapy. Boston: Little Brown, 1982:101-24.

5. Hershey CO, Tomford JW, McLaren CE, Porter DK, Cohen DI. The natural history of intravenous catheter-associated phlebitis. Arch Intern Med 1984;144:1373-5.

6. Bozzetti F, Terno G, Camerini E, Baticci F, Scarpa D, Pupa A. Pathogenesis and predictability of central venous catheter sepsis. Surgery 1982;91:383-9.

7. Lindblad B, Wolff T. Infectious complications of percutaneously inserted central venous catheters. Acta Anaesthesiol Scand 1985;29:587-9.

8. Michel L, McMichan JC, Beachy J-L. Microbial colonization of indwelling central venous catheters: statistical evaluation of potential contaminating factors. Am J Surgery 1979;137:745-8.

9. Sketch MH, Cale M, Mohiuddin SM, Booth RW. Use of 
percutaneously inserted venous catheters in coronary care units. Chest 1972;62:684-9.

10. Bernard RW, Stahl WM, Chase RM Jr. Subclavian vein catheterizations: a prospective study. II. Infectious complications. Ann Surg 1971;2:191-200.

11. Mogensen JV, Frederiksen W, Jensen JK. Subclavian vein catheterization and infection: A bacteriological study of 130 catheter insertions. Scand J Infect Dis 1972;4:31-6.

12. Mays ET. A microbiological investigation of percutaneous central venous catheters. South Med J 1972;65:830-2.

13. Hoshal VL Jr. Intravenous catheters and infection. Surg Clin North Am 1972;52:1407-17.

14. Buchsbaum HJ, White AJ. The use of subclavian central venous catheters in gynaecology and obstetrics. Surg Gynaecol Obstet 1973;136:561-3.

15. Powell-Tuck J, Lennard-Jones JE, Lowes JA, Danso KT, Shaw EJ. Intravenous feeding in a gastroenterological unit. A prospective study of infective complications. J Clin Pathol 1979;32:549-55.

16. Ryan JA Jr, Abel RM, Abbott WM, et al. Catheter complications in total parenteral nutrition. A prospective study of 200 consecutive patients. N Engl J Med 1974;290:757-61.

17. Sanders RA, Sheldon GF. Septic complications of total parenteral nutrition. A five year experience. Am J Surg 1976;132:214-20.

18. Curry CR, Quie PG. Fungal septicemia in patients receiving parenteral hyperalimentation. N Engl J Med 1971;285:1221-5.

19. Syndman DR, Prober BR, Murray SA, Gorbea HF, Majka JA, Perry K. Predictive value of surveillance skin cultures in total-parenteral-nutrition-related infection. Lancet 1982;ii:1185-8.

20. Linares J, Sitges-Serra A, Garau J, Perez JC, Martin R. Pathogenesis of catheter sepsis: a prospective study with quantitative and semiquantitative cultures of catheter hub and segments. J Clin Microbiol 1985;21:357-60.

21. Bjornson HS, Colley R, Bowen RG, Duty VP, Schwartz-Fulton JT, Fischer JE. Association between microorganism growth at the catheter site and colonization of the catheter in patients receiving total parenteral nutrition. Surgery 1982;92:720-5.

22. Syndman DR, Gorbea HF, Prober BR, Majka JA, Murray SA, Perry

LK. Predictive value of surveillance skin cultures in total parenteral nutrition-related infection. Lancet 1982;ii:1385-8.

23. Franceschi D, Gerding RL, Phillips G, Gratianne RB. Risk factors associated with intravascular catheter infections in burned patients: a prospective, randomized study. J Trauma 1989;29:811-6.

24. Mermel L, Stolz S, Maki DG. Epidemiology and pathogenesis of infection with Swan-Ganz catheters. A prospective study utilizing molecular subtyping. Am J Med 1991;91(3B):197S-295S

25. Conly JM, Stein K, Peters B. The pathogenesis of catheter-related infection in central venous catheters using gauze versus transparent dressings. In: Wadström T, Eliasson I, Holder I, Ljungh A, eds. Pathogenesis of Wound and Biomaterial Associated Infections. London: Springer-Verlag, 1990:507-17.

26. Zinner SH, Denny-Brown BC, Brawn P, Burke JP, Toala P, Kass $\mathrm{EH}$. Risk of infection with intravenous indwelling catheters: effect of application of antibiotic ointment. J Infect Dis 1969;120:616-9.

27. Norden CW. Application of antibiotic ointment to the site of venous catheterization - a controlled trial. J Infect Dis $1969 ; 120: 611-5$

28. Maki DG, Band JD. A comparative study of polyantibiotic and iodophor ointments in prevention of catheter-related infection. Am J Med 1981;70:739-44

29. Levin A, Mason AJ, Jindal KK, Goldstein MB, Fong IW. The value of topical povidone-iodine (PV-I) ointment in the prevention of haemodialysis related sepsis. 29th Interscience Conference on Antimicrobial Agents and Chemotherapy. Houston, Texas, 1989. (Abst 1078)

30. Prager RL, Silva J. Colonization of central venous catheters. South Med J 1984;1;77:458-61.

31. Casewell MW, Hill RLR. In vitro activity of mupirocin (pseudomonic acid) against clinical isolates of Staphylococcus aureus. J Antimicrob Chemother 1985;15:523-31.

32. Caswell MW, Hill RLR. Mupirocin (pseudomonic acid) - A promising new topical antimicrobial agent. J Antimicrob Chemo 1987;19:1-5.

33. Hill RLR, Fisher AP, Ware RJ, Wilson S, Caswell MW. Mupirocin for the reduction of colonization of internal jugular cannulae - A randomized controlled trial. J Hosp Infect 1990;15:311-21.

34. Stillman RM, Soliman P, Garcia L, Sawyer PN. Etiology of catheter-associated sepsis. Correlation with thrombogenicity. Arch Surg 1977;112:1497-9.

35. Brun-Buisson C, Fekri A, Legrand P, Huet Y, Larabi S, Rapin M. Diagnosis of central venous catheter-related sepsis. Arch Intern Med 1987;147:873-7.

36. Balows A, Hausha WJ, Hausler WJ, et al. Manual of Clinical Microbiology. 5th edn. Washington: American Society for Microbiology, 1991:59-137.

37. Maki DG, Weise CE, Sarafin HW. A semiquantitative culture method for identifying intravenous catheter related infection. N Engl J Med 1977;296:1305-9.

38. Christensen GD, Simpson WA, Bisno AL, Beachey EH. Adherence of slime-producing strains of Staphylococcus epidermidis to smooth surfaces. Infect Immun 1982;37:318-26.

39. Cooksey RC, Baldwin JN. Relatedness of tetracycline resistance plasmids among species of coagulase-negative staphylococci. Antimicrob Agents Chemother 1985;27:234-8.

40. Stiges-Serra A, Puing P, Linares J, et al. Hub colonization as the initial step in an outbreak of catheter-related sepsis due to coagulase-negative staphylococci during parenteral nutrition. J Parenter Enteral Nutr 1984;8:668-72.

41. Ward A, Campoli-Richards DM. Mupirocin: A review of its antibacterial activity, pharmacokinetic properties and therapeutic use. Drugs 1986;32:425-44.

42. Parenti MA, Hatfield SM, Leyden JJ. Mupirocin: A topical antibiotic with a unique structure and mechanisms of action. Clin Pharm 1987;6:761-70.

43. Bulanda M, Gruszka M. Heczko B. Effect of mupirocin on nasal carriage of Staphylococcus aureus. J Hosp Infect 1989;14:117-24

44. Hill RL, Duckworth GJ, Casewell MW. Elimination of nasal carriage of methicillin-resistant Staphylococcus aureus with mupirocin during a hospital outbreak. J Antimicrob Chemother 1988;22:377-84

45. Hill RLR, Casewell MW. Reduction in the colonization of central venous cannulae by mupirocin. J Hosp Infect 1991;19(Suppl B):47-57.

46. Conly JM, Grieves K, Peters B. A prospective randomized study comparing transparent and dry gauze dressings for central venous catheters. J Infect Dis 1989;159:310-9.

47. Hoffmann KK, Weber DJ, Samsa GP, Rutala WA. Transparent polyurethane film as an intravenous catheter dressing: a meta-analysis of the infection risks. JAMA 1992;267:2072-6.

48. Norwood SH, Jenkins G. An evaluation of triple-lumen catheter infections using a guide-wire exchange technique. J Trauma 1990;30:706-12.

49. Band JD, Maki DG. Infections caused by arterial catheters used for hemodynamic monitoring. Am J Med 1979;67:735-41. 


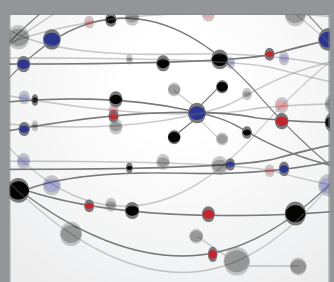

The Scientific World Journal
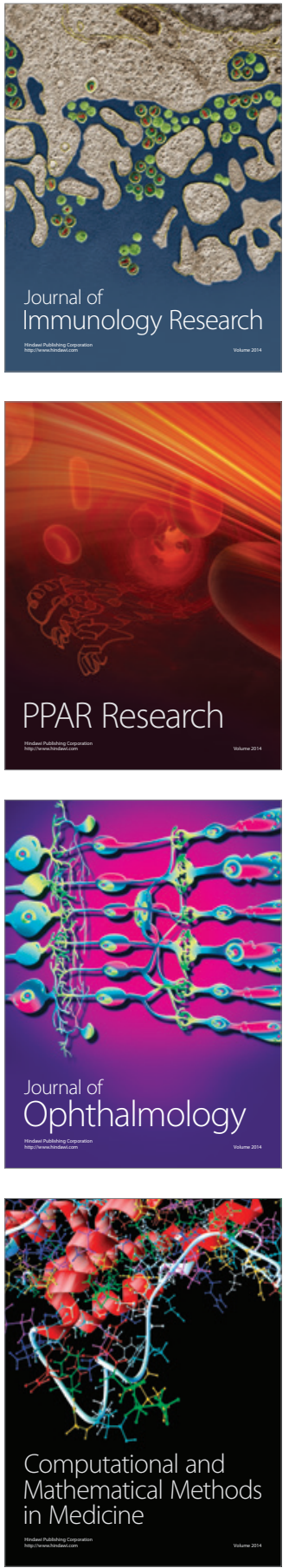

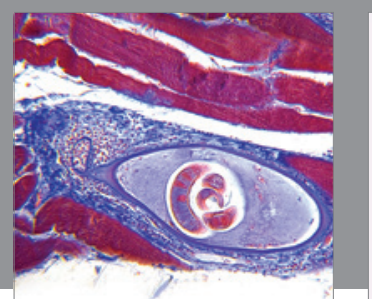

Gastroenterology Research and Practice

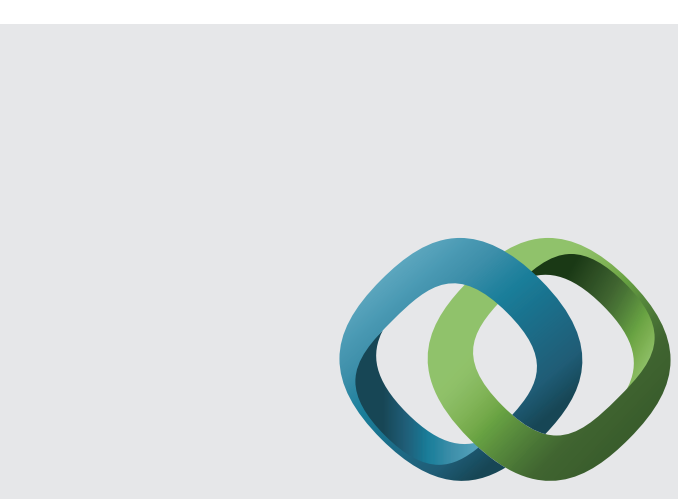

\section{Hindawi}

Submit your manuscripts at

http://www.hindawi.com
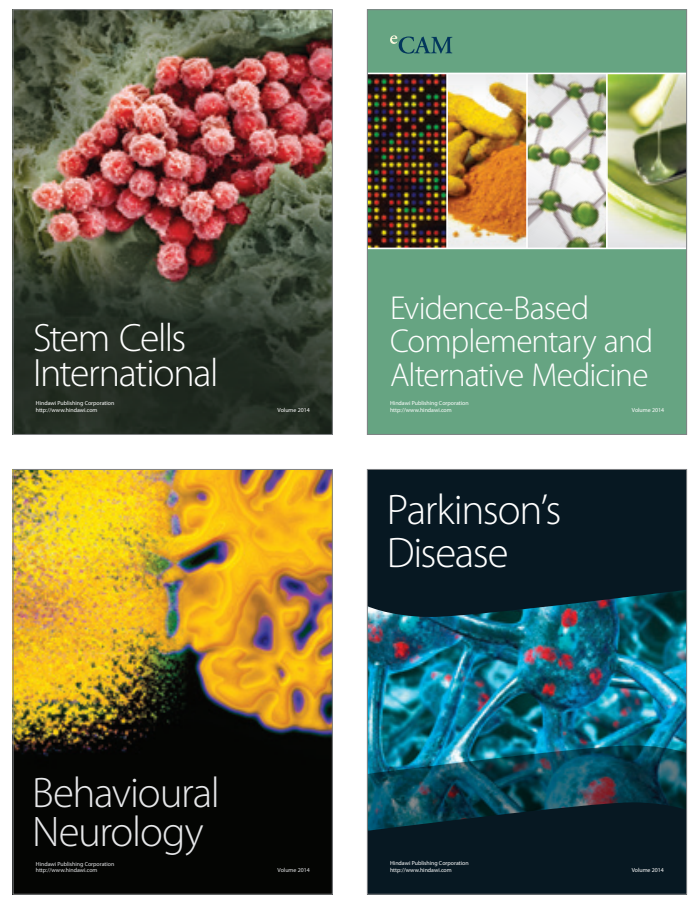
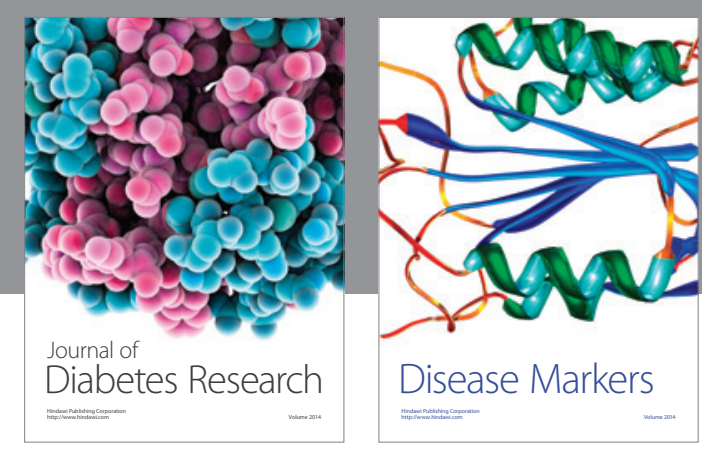

Disease Markers
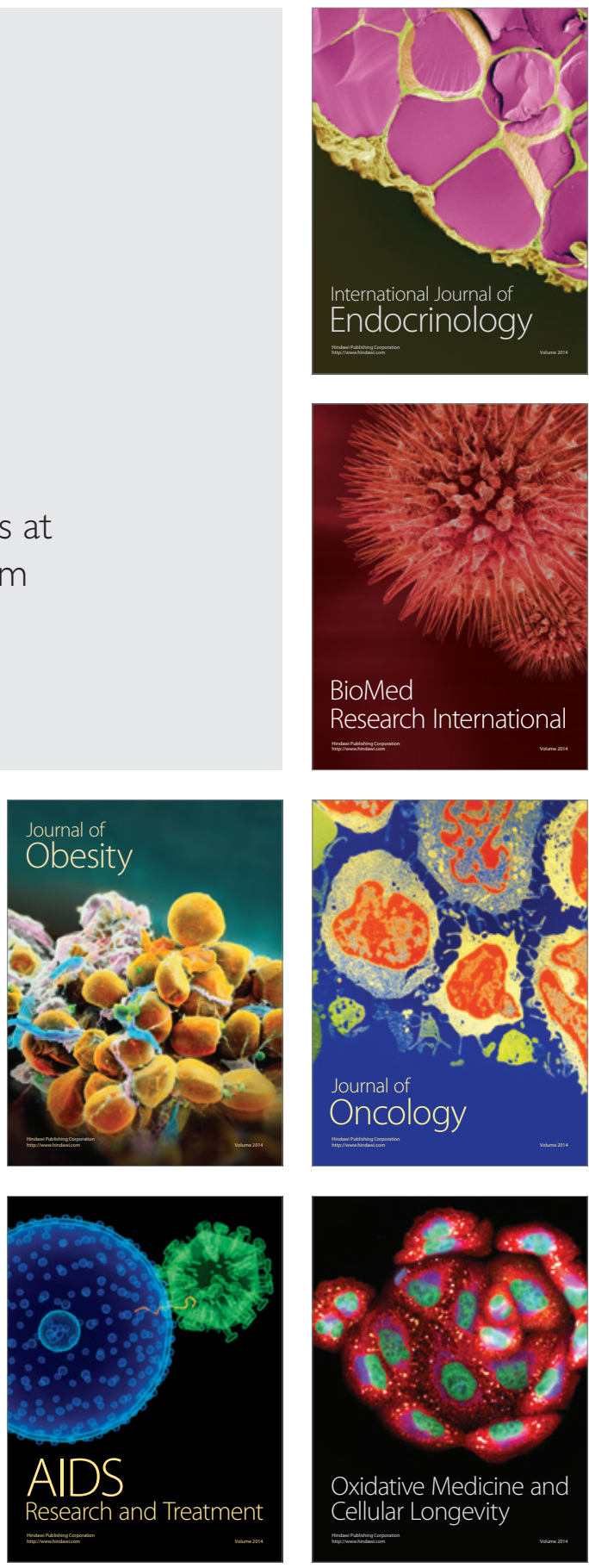